\title{
Design of Variable Gain Amplifier Circuit Based on Newton Rings Stress
}

\author{
Changli Guo \\ College of Science \\ Xi'an University of Science and Technoligy \\ Xi'an, China \\ E-mail: 979865758@qq.com \\ Shouquan Wang \\ College of Science \\ Xi'an University of Science and Technoligy \\ Linyi, China \\ E-mail: qserwa@163.com
}

\author{
Yu Chai \\ Electrical Engineering and Automation \\ Xi'an University of Science and Technoligy \\ Xi'an, China \\ E-mail: 312846544@qq.com \\ Zhaoxia Guo \\ College of Science \\ Xi'an University of Science and Technoligy \\ Xi'an, China \\ E-mail: 1084583535@qq.com
}

\begin{abstract}
On the purpose of measuring Newton rings deformation stress and the intelligentialize of the newton rings apparatus, a Variable Gain Amplifier circuit which is based on a low power, general purpose instrumentation amplifiers INA128 offering excellent accuracy was designed to amplify the low frequency and voltage signal from the Pressure sensor. The principle of circuit and the information of chips used were introduced detailedly. Intermediately, problem which appeared in the program of the design had been figured out. Finally, test the performance of the circuit and analyze the experimental data with MATLAB, results were as follws, when the gain is equal to $33.97 \mathrm{~dB}$ (Magnified 50 times), the bandwidth is up to $599 \mathrm{kHz}$; when the gain is equal to $40 \mathrm{~dB}$ (Magnified 100 times), the bandwidth is up to $250 \mathrm{kHz}$; when the gain is equal to $53.98 \mathrm{~dB}$ (Magnified 500 times), the bandwidth is up to $39 \mathrm{kHz}$.
\end{abstract}

key words-gain variable; Amplifier circuit; nstrumentation;

newton rings;INA128.

\section{INTRODUCTION}

It is necessary that the newton rings apparatus ${ }^{[1]}$ need to be made a change for the intelligentialize and research activity. Intelligent consists of the following aspects, on the one hand, the accuracy of newton rings apparatus should be improved; on the other hand, instead of reading the microscope with your eyes immediately, you can observe the picture of the microscope through the display, and you can measure the parameters of the picture by the way of image processing. An amplifier circuit must be designed to meet the needs of improving the accuracy of newton rings apparatus.

\section{SYSTEM BLOCK DIAGRAM AND SCHEMATIC DIAGRAM}

INA128 is chosen from all sorts of amplifiers, and high precision linear regulated power supply should be provided for it. As shown in Fig 1, The INA128 is low power, general purpose instrumentation amplifiers offering excellent accuracy ${ }^{[2]}$. For example, it can magnify the small-signal from gravity sensor.

Fig 2 shows the schematic diagram which is based on the system block diagram.

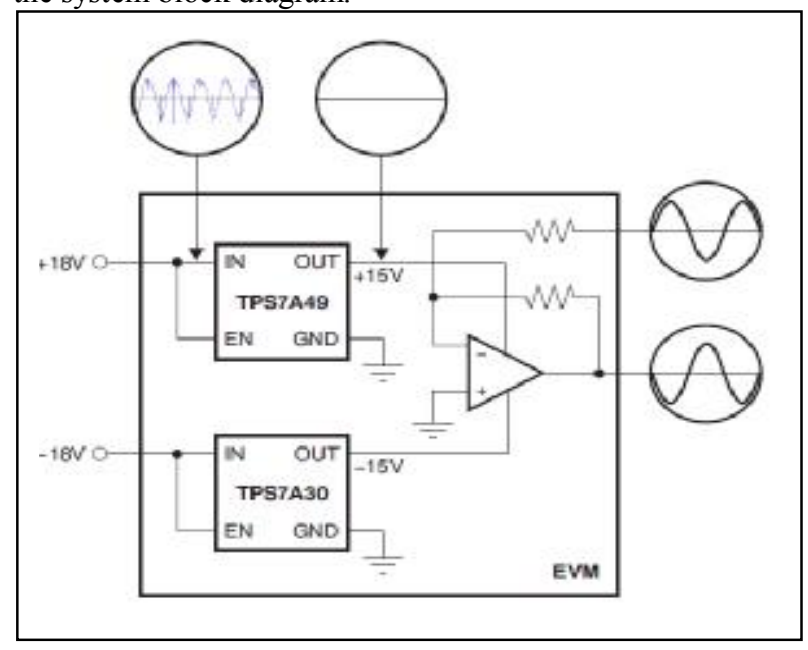

Figure 1. AMPLIFIER SYSTEM BLOCK DIAGRAM

III. THE PRINCIPLE OF THE MAIN CHIP

A. INA128

The INA128 are low power, general purpose instrumentation amplifiers offering excellent accuracy. The versatile 3-op amp design and small size make them ideal for a wide range of applications. Current-feedback input circuitry provides wide bandwidth even at high gain $(200 \mathrm{kHz}$ at $\mathrm{G}=100)$. A single external resistor sets any gain from 1 to 10,000 . RG connected between pins 1 and 8 . It is easy to use the INA128, and when we put the slide rheostat to take the place of the $R G$, a variable gain amplifier can be designed. Gain formula ${ }^{[2]}$ : 


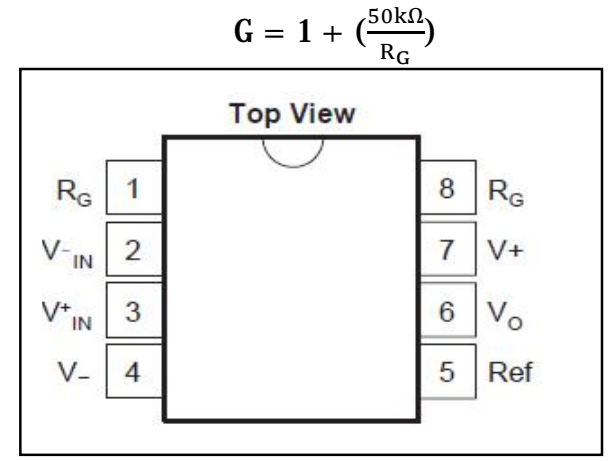

Figure 3. INA128 PIN CONFIGURATION

\section{B. TPS7A4901 and TPS7A3001}

The parameters and usage of TPS7A4901 and TPS7A3001 are basically same. The only difference is that TPS7A4901 is a positive linear regulator, but TPS7A3001 is negative linear regulator. For the reason, they are usually used in pairs to provide positive and negative power supply. So we will illustrate the usage of two linear regulators with TPS7A4901 ${ }^{[3]}$.

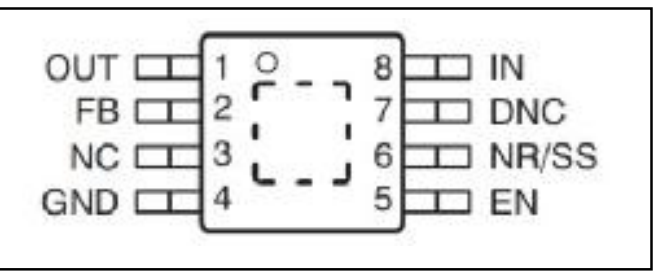

Figure 4. TPS7A4901 PIN

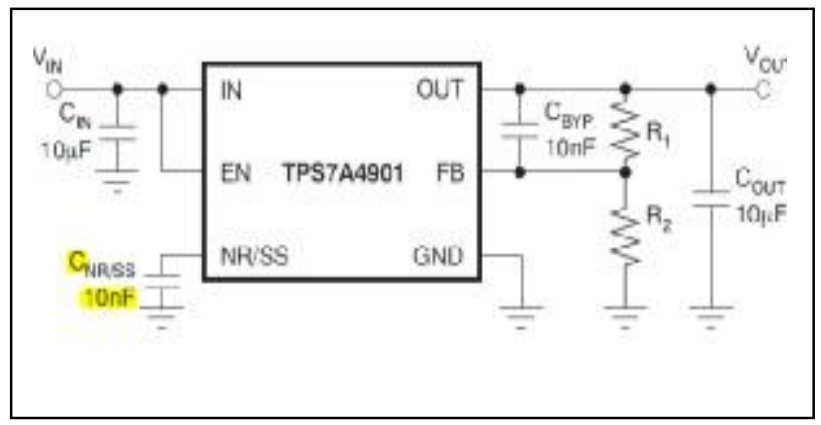

Figure 5. TYPICAL APPLICATION CIRCUIT

The TPS7A4901 has an output voltage range of +1.194 to $+33 \mathrm{~V}$. The nominal output voltage of the device is set by two external resistors, as shown in Figure. $R_{1}$ and $R_{2}$ can be calculated for any output voltage range using the formula shown in (2) To ensure stability under no load conditions, this resistive network must provide a current equal to or greater than $5 \mu \mathrm{A}^{[3]}$.

$$
\mathrm{R} 1=\mathrm{R} 2\left(\frac{\mathrm{V}_{\mathrm{OUT}}}{\mathrm{V}_{\mathrm{FB}}}-1\right)
$$

$\mathrm{V}_{\mathrm{FB}}$ is $1.18 \mathrm{~V}$ because of the device characteristics ${ }^{[2]}$.

\section{MODULE PERFORMANCE TEST}

The test of module is mainly divided into two aspects. Firstly, test the performance of the linear power, then test the performance of the amplifier.

\section{A. Test of linear regulated power supply module:}

It must be sure that whether the performance of the power module is meet the requirements before testing the amplifier $^{[4-6]}$. Fig 6 shown the Printed Circuit Board(PCB).

Table 1 shows the definition of the pin in the amplifier PCB.

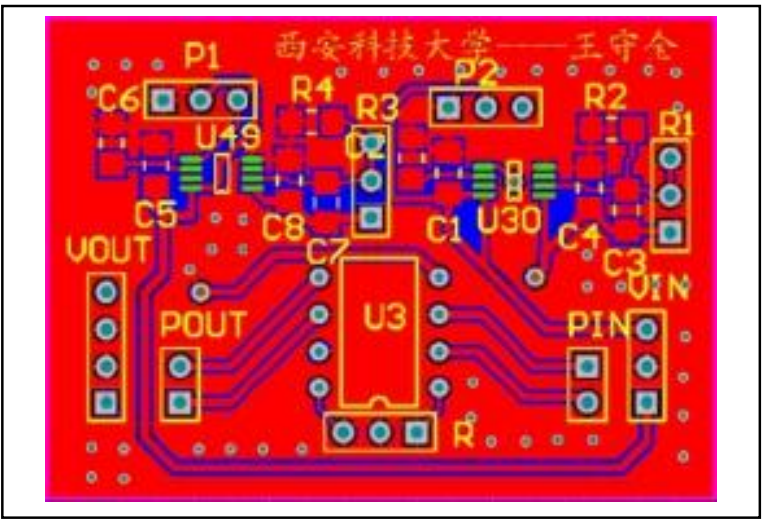

Figure 6. AMPLIFIER PCB

TABLE I. PIN DEFINITION

\begin{tabular}{|c|c|c|}
\hline Sill-screen & Direction & Function \\
\hline VIN & Input & Input of external power \\
\hline VOUT & Output & $\begin{array}{c}\text { Output voltage value of linear } \\
\text { regulated power supply }\end{array}$ \\
\hline PIN & Input & Input of external signal \\
\hline POUT & Output & Output of amplifying signal \\
\hline
\end{tabular}

With adjusting the slide rheostat of $R_{1}$ and $R_{3}$ the output voltage can be changed to power INA128. It is important to note that the absolute value of external voltage must be bigger $2 \mathrm{~V}$ than what you want to get, for example, if you want to supply INA128 with $\pm 15 \mathrm{~V}$, the external input voltage is \pm 17 at least.

B. amplifying circuit performance test (amplitude-

frequency response):

The main instrument: signal generator, oscilloscope, several wires and voltmeter.

Here are several typical gain according to the INA128 gain formula ${ }^{[2]}$ : $\mathrm{RG}=1 \mathrm{~K} \Omega, \mathrm{G}=33.98 \mathrm{~dB}$ 。 $\mathrm{RG}=500 \Omega$, $\mathrm{G}=40 \mathrm{~dB}$ 。 $\mathrm{RG}=100 \Omega, \mathrm{G}=53.98 \mathrm{~dB}$.

Using MATLAB software to draw the amplitudefrequency response curve $\mathrm{e}^{[7-9]}$. As shown in figure 4.

Due to the limitation of the signal generator, the signal amplitude is set $0.05 \mathrm{~V}$, and frequency was gradually increased from $5 \mathrm{~Hz}$. 
TABLE II. CUT-OFF FREQUENCY OF THE TYPECAL GAIN

\begin{tabular}{|c|c|}
\hline Gain & Cut-off frequency \\
\hline $\mathrm{G}=33.98 \mathrm{~dB}$ & $599 \mathrm{KHz}$ \\
\hline $\mathrm{G}=40 \mathrm{~dB}$ & $250 \mathrm{KHz}$ \\
\hline $\mathrm{G}=53.98 \mathrm{~dB}$ & $39 \mathrm{KHz}$ \\
\hline
\end{tabular}

Table 2 shows the cut-off frequency of the typical gain which obtained from figure 4. Obviously, when the gain is equal to $33.97 \mathrm{~dB}$ (Magnified 50 times), the bandwidth is up to $599 \mathrm{kHz}$; when the gain is equal to $40 \mathrm{~dB}$ (Magnified 100 times), the bandwidth is up to $250 \mathrm{kHz}$; when the gain is equal to $53.98 \mathrm{~dB}$ (Magnified 500 times), the bandwidth is up to $39 \mathrm{kHz}$.

\section{CONCLUSION}

According to the measured data, both magnification and bandwidth conform to the need of intelligent newton rings apparatus, and it will provide guarantee for the newton rings apparatus acquiring accurate data. Nevertheless, what we did is the beginning of intelligent newton rings apparatus, the mechanical structure of newton rings apparatus must be transform to meet the needs of measurement

\section{REFERENCES}

[1] Lu. Ming-Feng, Ni. Guo-Qiang, Bai. Ting-Zhu, Tao. Ran, and Zhang. Feng, "Method for suppressing the quantization error of Newton's rings fringe pattern"Optical Engineering, vol 52, n 10, 2013

[2] Information

in "http://www.ti.com.cn/product/cn/INA128?keyMatch=INA128\&tis earch=Search-CN-Everything"

[3] "TPS7A30-49EVM-567" user's guide

[4] Shiau. Jaw-Kuen, Wei. Yu-Chen, and Lee. Min-Yi, "Fuzzy controller for a voltage-regulated solar-powered MPPT system for hybrid power system applications" Source: Energies, vol 8, n 5, p 3292-3312, 2015

[5] Umamaheswari, M.G. Uma. G, "Analysis and design of reduced order linear quadratic regulator control for three phase power factor correction using Cuk rectifiers", Source: Electric Power Systems Research, vol 96, p 1-8, 2013

[6] Nasir, Saad Bin, Lee. Youngtak, Raychowdhury. Arijit, "Modeling and analysis of system stability in a distributed power delivery network with embedded digital linear regulators" Source Proceedings - International Symposium on Quality Electronic Design, ISQED, p 68-75, 2014,

[7] Zhu. Yongsong, "Implementation and application of a class chaos model based on matlab," Source: Proceedings of the 2nd International Conference on Modelling and Simulation, ICMS2009, vol 5, p 492-496, 2009

[8] Jiang, Lei, "Research on the programming of calculation and analysis of the improved finite element method based on matlab," Source: Applied Mechanics and Materials, vol 602-605, p 33163320, 2014

[9] Gu, Hailan, Zhang, Wei, "An experimental study of college teaching based on matlab software," Source: Proceedings - 2012 5th International Conference on Intelligent Computation Technology and Automation, ICICTA 2012, p 69-71, 2012

[10] YU Guan-cheng, ZHAO Xiao-dong, YU Qian. Ultra-low power consumption intelligent mobile ECG monitoring device

[11] DENG Sen-yang, ZHANG Wan-li, PENG Bin.Research on time doma in windowing technique in improving passive wireless SAW sensor measurement [J].Transducer and Microsystem Technologies.2015. Vol.34. No.3

[12] CHEN Cheng-ying, HEI Yong, HU Xiao-yu. A Low Power Variable Gain Amplifier for Hearing Aid SoC [J]. Microelectronics. Dec. 2014. Vol.44. No.6.

[13] ZHANG Min-san, WU Hai-bo. Design of high-precision weighing system [J]. Transducer and Microsystem Technologies. 2014. Vol.33. No.12.

[14] HAN Qin-xia. Digitalized mine heterogeneous information integration processing model based on internet of things [J]. Journal of Xi'an University of Science and Technology, Jan.2015.Vol.35 No.1.

[15] Li Cheng-lin, Liu Yong, Fang Tao, Design of gain adjustable RF broadband amplifier [J].Electronics Design \& Application. Feb. 2015 


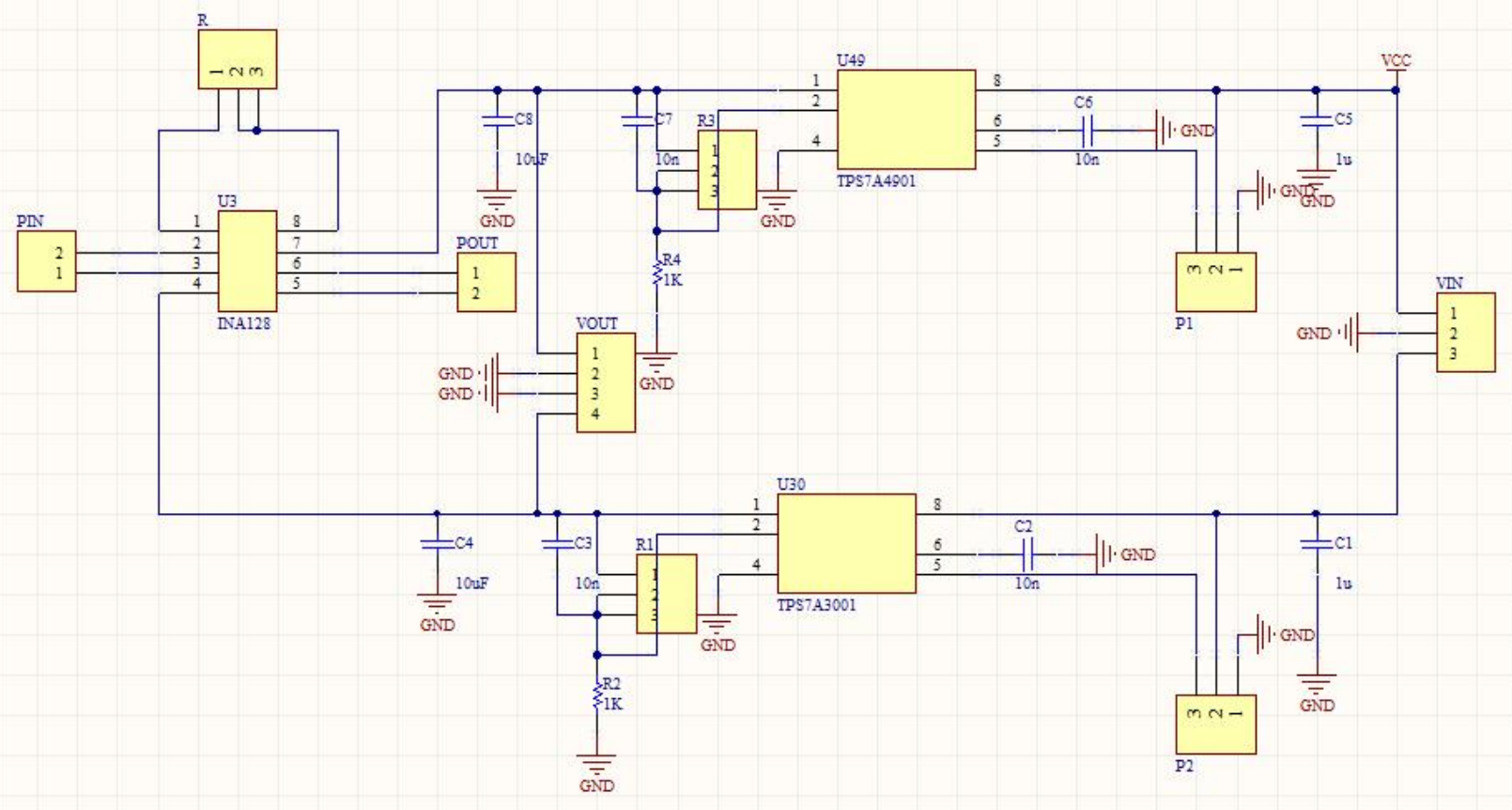

Figure 2. AMPLIFIER SCHEMATIC DIAGRAM

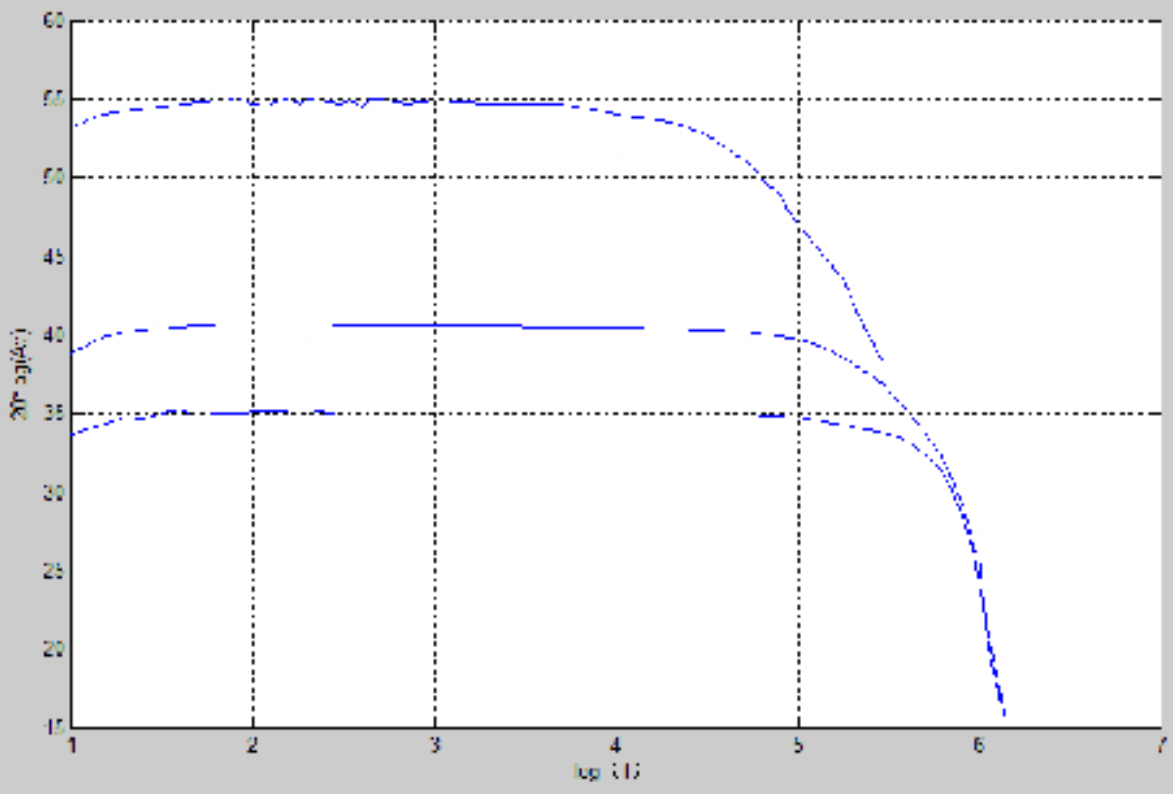

Figure 7. AMPLITUDE-FREQUENCY RESPONSE CURVE 